\title{
Rentabilidade da produção de ovinos de corte em pastagem e em confinamento ${ }^{1}$
}

\author{
Carina Simionato de Barros ${ }^{2,4}$, Alda Lúcia Gomes Monteiro² ${ }^{2}$ César Henrique Espírito Candal \\ Poli $^{3}$, João Ricardo Dittrich ${ }^{2}$, José Roberto Fernandes Canziani ${ }^{2}$, Maria Angela Machado \\ Fernandes ${ }^{2,5}$
}

\author{
1 Pesquisa financiada pelo CNPq. \\ 2 Universidade Federal do Paraná. \\ 3 Universidade Federal do Rio Grande do Sul. \\ ${ }^{4}$ Bolsista CNPq. \\ 5 Bolsista CAPES.
}

RESUMO - Os objetivos neste trabalho foram analisar a viabilidade econômica de sistemas de produção de cordeiros e identificar os componentes de maior influência no custo de produção. O estudo foi realizado em duas etapas. Na etapa 1, realizouse a comparação de quatro sistemas de terminação de cordeiros: 1) desmame aos 60 dias e terminação em pasto; 2) cordeiro com mãe em pasto; 3) cordeiro com mãe em pasto e concentrado (1\% PC/dia) em creep feeding; e 4) desmame aos 60 dias e confinamento. Na etapa 2, um módulo de 150 ovelhas em 9 ha de pasto cultivado nos sistemas em pastagem e 7 ha no confinamento foi proposto a partir do experimento para avaliações econômicas, considerando a venda de cordeiro vivo terminado ou abate e venda de carne, além da venda de matrizes. Foram realizados cálculos de custo fixo (depreciação), variável (materiais, mão-de-obra, transporte, abate, juros, conservação, despesas gerais) e total (fixo+variável), lucratividade e rentabilidade, valor presente líquido, taxa interna de retorno e custo/benefício. O maior custo total foi observado no confinamento e o menor, no sistema de cordeiro terminado com a mãe em pasto. A margem líquida na venda de cordeiros foi negativa em todos os sistemas. A venda de carne apresentou margem líquida negativa apenas para terminação em confinamento. A taxa interna de retorno para venda de carne foi: $1,4 \%$ no desmamado em pasto; $4,3 \%$ no de cordeiro com mãe em pasto; $2,1 \%$ no creep feeding; e -2,3\% no confinamento. Os componentes do custo operacional total com maior influência sobre o custo de produção nos sistemas a pasto, em ordem decrescente, foram mão-de-obra e alimentação; no confinamento, foram alimentação e mão-de-obra. A venda da carne apresentou lucratividade maior que a venda de cordeiro vivo, com maior valor no sistema sem desmame terminado na pastagem.

Palavras-chave: custo de produção de ovinos, lucratividade da criação de ovinos, margem da venda de cordeiro, resultado econômico da criação ovina, venda de carne ovina

\section{Economic return of sheep production on pasture and in feedlot}

\begin{abstract}
The objectives of this study were to analyze the economic viability of meat lamb production systems and identify the components with greatest influence on production cost. The study was carried out in two stages. Stage 1: comparison of finishing lamb production systems: (1) lambs weaned at 60 days and finished on pasture; (2) lambs with mother on pasture; (3) lambs with mother on pasture plus concentrate (1\% BW/day) in creep feeding; and (4) lambs weaned at 60 days and feedlot. Stage 2: a module of 150 ewes on 9 ha of pasture cropped in the pasture systems and 7 ha in feedlot was proposed after the economic assessment experiment, considering the sale of finished lamb or slaughter and sale of meat, and the sale of animals for reproduction. The fixed cost (depreciation), variable cost (materials, labour, transport, slaughter, interest, conservation, general expenses), total cost (fixed+variable), profitability, economic return, present net worth, intern return rate and benefit:cost ratio were calculated. The highest total cost was observed on feedlot and the lowest in lamb finished with dams on pasture. The net margin of lamb sale was negative in all systems. Meat sale showed negative net margin only for lambs on feedlot. Internal rate of return for meat sale was: $1.4 \%$ for lambs with mother on pasture; $4.3 \%$ for no weaning on pasture; $2.1 \%$ for lambs in creep feeding; and $-2.3 \%$ for lambs in feedlot. Items of total operational cost with the greatest influence on systems in pasture, in decreasing order, were labour and feeding. Sale of meat was more profitable than sale of live lambs with greatest value in the system where lambs had been kept with mother on pasture.
\end{abstract}

Key Words: economic result of sheep production, lamb sale income, sheep production cost, sheep production profitability, sheep meat sale 


\section{Introdução}

Com aumento do interesse dos ovinocultores em intensificar a produção, são importantes informações para auxiliar produtores que têm como desafio aumentar a produção de carne para atender um mercado exigente. Nesse contexto, estudos sobre sistemas de terminação de cordeiros devem ser realizados considerando os aspectos produtivos, econômicos e de sustentabilidade com objetivo do produtor permanecer na atividade.

A terminação de cordeiros pode ser feita sem desmame com efeitos benéficos aos cordeiros (Cañeque et al., 1992), e a ausência do desmame pode contribuir para melhor desempenho por evitar estresse. Segundo Brown (1994), não existe finalidade em antecipar o desmame se as condições ambientais propiciam engorda ao pé da mãe, com alto desempenho, salvo se o leite é requerido para outros propósitos. Para alto desempenho e reduzida idade de abate, o pasto deve proporcionar oferta de forragem para seleção de dieta, constituída sobretudo por folhas (Frescura et al., 2005). O uso do creep feeding em pasto pode aumentar o ganho médio diário e reduzir o tempo de abate e, segundo Neres et al. (2001), é valiosa ferramenta para obtenção de bons resultados zootécnicos e econômicos. Ribeiro et al. (2009) confirmaram parte dessas vantagens e observaram desempenho superior de cordeiros terminados ao pé da mãe em pasto de azevém (261 g/dia) em comparação aos desmamados (108 g/dia).

A terminação de cordeiros com desmame é uma alternativa. Quando realizada em pasto sem suplementação, deve-se considerar: área, disponibilidade de forragem e carga animal. Nesse sistema, a verminose pode elevar a mortalidade e reduzir o rendimento de carcaça (Ribeiro et al., 2009). No confinamento, deve-se observar o alto custo com alimentação e infraestrutura; entretanto, há maior ganho de peso individual, menor idade de abate e maior giro de capital (Lopes \& Magalhães, 2005).

O desempenho dos animais e as características da carcaça são estudados em sistemas de terminação de cordeiros, entretanto, a análise econômica não é realizada, apesar de ser importante e permitir o conhecimento detalhado dos custos de produção. Isso é importante para auxiliar na melhoria da produtividade com lucratividade.

Os objetivos neste trabalho foram identificar o sistema de terminação que apresenta menor custo de produção e os componentes de maior influência sobre esse custo e analisar a viabilidade econômica dos sistemas de cordeiros para carne.

\section{Material e Métodos}

O trabalho foi realizado em duas etapas: 1) realização do experimento estudando os sistemas de terminação, no Laboratório de Produção de Ovinos e Caprinos (LAPOC) na Fazenda Experimental da Universidade Federal do Paraná, localizada em Pinhais-PR (2525' Sul e 49² $8^{\prime}$ Oeste, 915 m acima do nível do mar); e 2) elaboração de projeto com módulos de 150 matrizes a partir dos sistemas avaliados para a análise econômica.

O experimento foi realizado no período de outubro de 2003 a janeiro de 2004, no qual quatro sistemas distintos de terminação de cordeiros foram executados, até o abate. cordeiros desmamados mantidos em pasto; cordeiros mantidos com as ovelhas em pasto; cordeiros mantidos com as ovelhas em pasto recebendo suplementação em creep feeding ( $1 \%$ do peso dos cordeiros) e cordeiros desmamados e confinados. O delineamento experimental foi inteiramente casualizado com três repetições por sistema. Quatro cordeiros-testes foram avaliados por repetição, sendo um macho e uma fêmea de parto simples e um casal de parto gemelar. Os animais utilizados foram da raça Suffolk e a pastagem utilizada foi Cynodon spp. cultivar Tifton 85 (capim-tifton 85). No período de junho até o início de novembro havia disponibilidade de Lolium multiflorum (azevém) que havia sido sobressemeado no capim-tifton 85 no inverno de 2003. Os animais foram abatidos aos $32 \mathrm{~kg}$ de peso corporal pela média dos sistemas.

O suplemento fornecido no creep feeding consistia de concentrado (19,42\% PB; 72,62\% NDT), na quantidade de $1 \%$ do peso corporal dos cordeiros em instalação específica no pasto. Os cordeiros em confinamento foram alimentados com $40 \%$ de concentrado (o mesmo do creep feeding) e 60\% de feno de alfafa (18,99\% PB; 52,96\% NDT), que foi fornecido à vontade, considerando recomendações do NRC (1985) para elevado crescimento.

O exame coproparasitológico foi realizado para controle da verminose pelo método modificado de Gordon \& Whitlock (1939). Quando os animais apresentaram OPG acima de 500, foram desverminados com os princípios ativos à base de nitroxinil e moxidectina, cuja associação apresentava eficácia comprovada no rebanho. O número de desverminações e as doses dos anti-helmínticos no período foram registrados. Também foi avaliada a infecção por Eimeria spp. e animais que apresentavam sinais clínicos de eimeriose foram tratados.

Na etapa 2 do trabalho, a partir dos dados obtidos no experimento, foi realizada projeção para um módulo de 150 ovelhas, quatro reprodutores e dois rufiões para cada um 
dos quatro sistemas. Assim, considerou-se propriedade rural já existente, com os mesmos padrões adotados no experimento. O número de animais mantidos no rebanho foi pré-fixado, portanto não se considerou crescimento do mesmo. O excedente de animais foi considerado como vendido.

Os coeficientes técnicos anuais do rebanho foram aqueles médios observados no LAPOC; 95\% de fertilidade, $90 \%$ de natalidade, prolificidade de 1,2 cordeiros por ovelha, $4 \%$ de mortalidade de animais adultos, 3\% de mortalidade de cordeiros até 60 dias, descarte de $10 \%$ das ovelhas, descarte de um rufião e um reprodutor. Foi realizada uma estação de monta por ano.

Considerou-se que as ovelhas permaneceram em pastagem durante o ano todo, em sistema de pastejo contínuo, com oferta de $8 \%$ do peso dos animais em matéria seca de forragem de julho a fevereiro, e redução de oferta entre $3 \%$ e $4 \%$ de fevereiro a maio. No mês de fevereiro, foi realizado flushing e, em período de 15 dias pré-monta, foram ofertados 300 gramas de concentrado (16\% PB; 74\% NDT) por dia para cada ovelha, conforme recomendações do NRC (1985), sendo o custo desse concentrado R \$ 0,35/kg. No mês de maio, devido à baixa disponibilidade de pasto, houve necessidade de suplementação de volumoso, com oferta de 500 gramas de MS de pré-secado de aveia (13\% PB; $53 \%$ NDT) por ovelha por dia, com custo do volumoso de $\mathrm{R} \$ 0,16 / \mathrm{kg}$. Os machos (reprodutores e rufiões) permaneceram separados das fêmeas fora do período da monta; com manejo semelhante fornecendo a mesma suplementação volumosa. A suplementação foi fornecida nos piquetes. $\mathrm{O}$ sal mineral foi disponibilizado aos animais durante o ano todo para consumo médio diário de 20 gramas por animal adulto, com custo de R $\$ 0,80 / \mathrm{kg}$. Os alimentos utilizados para a terminação dos cordeiros apresentaram os seguintes custos: feno de alfafa, R $\$ 0,60 / \mathrm{kg}$ e concentrado $20 \% \mathrm{~PB}$, $\mathrm{R} \$ 0,40 / \mathrm{kg}$.

Os custos com o pasto incluíram os insumos utilizados, como calcário, adubos e sementes, e o aluguel de máquinas para aplicação de adubos e plantio. A depreciação anual da pastagem foi calculada pelo somatório dos insumos necessários para formação do pasto perene (capim-tifton 85) dividido pelo período de dez anos (Canziani \& Dossa, 2000).

Elaborou-se inventário da terra e das benfeitorias necessárias para os sistemas com determinação de custo do bem novo e da vida útil. Nos quatro sistemas, considerou-se área de nove hectares de pastagem formada de capim-tifton $85,1,8$ ha de reserva legal, 0,6 ha de reserva permanente. Uma área ocupada com benfeitorias foi incluída, com 0,06 ha no sistema com confinamento de cordeiros e 0,02 ha nos demais sistemas, num total de 11,42 ha. Nos quatro sistemas considerou-se uma casa de $40 \mathrm{~m}^{2}$, um escritório de 5 m² e cercas eletrificadas com três fios. O depósito foi de $50 \mathrm{~m}^{2}$ nos sistemas com cordeiros desmamados e sem desmame mantidos em pasto, e de $100 \mathrm{~m}^{2}$ no sistema de cordeiro desmamado confinado e com creep feeding, em decorrência da necessidade de espaço para armazenar suplementos alimentares. No confinamento de cordeiros utilizou-se aprisco de $300 \mathrm{~m}^{2}$ para terminação; nos demais, considerou-se instalação de $30 \mathrm{~m}^{2}$ para abrigo eventual. As máquinas e os equipamentos considerados nos quatro sistemas de produção foram uma roçadeira, uma balança para pesagem dos animais e uma geladeira. Somou-se o valor de todas as máquinas e equipamentos e atribuiu-se $5 \%$ sobre esse valor para outros equipamentos como instrumentos para casqueamento, tosquia, identificadores, entre outros. Quatro freezers para armazenamento de carne congelada foram incluídos nos cálculos da venda de carne congelada com conservação na propriedade.

Para cálculo de conservação e reparos, considerou-se $2 \%$ do valor de cada benfeitoria por ano. Para geladeira, freezer e roçadeira, estabeleceu-se taxa de conservação e reparos de 30\% do valor novo por ano e para balança e outros equipamentos, 5\% ao ano. A depreciação foi obtida pela fórmula: (valor inicial do bem-20\% do valor inicial, o qual é o valor sucata)/vida útil. Para as benfeitorias considerou-se vida útil de 30 anos para residência, aprisco e escritório, 15 anos para o depósito e 25 anos para cercas. Para cercas considerou-se valor residual igual à zero, assim como para geladeira, freezer e outros equipamentos. Os coeficientes técnicos citados foram recomendados em SistemaFAEP(2005).

Os custos com medicamentos foram estimados com base no consumo da fazenda da UFPR. Os custos com vacinação incluíram uma dose da vacina contra clostridioses nas ovelhas e uma dose nos cordeiros.

O consumo de energia elétrica estimado foi baseado em informações obtida em COPEL (2007).

O custo considerado para transporte e abate foi de $\mathrm{R} \$ 2,00$ e R \$10,00, respectivamente, por animal e foi obtido por meio de orçamento em abatedouro que realiza o abate e entrega as carcaças divididas ao meio, embaladas e congeladas, devidamente inspecionadas.

O custo mensal com assistência técnica foi de $0,8 \mathrm{vez}$ salário mínimo regional $(\mathrm{R} \$ 437,80)$ nos sistemas de cordeiro desmamado e não-desmamado terminado em pasto, e 0,6 salário mínimo regional nos sistemas de terminação em pasto sem desmame com creep feeding e com confinamento.

A taxa de juros sobre o capital de giro (custo variável menos custos com transporte e abate, assistência técnica, impostos e taxas e despesas gerais) foi de $4 \%$ ao ano, que é a taxa do financiamento da produção da agricultura familiar por meio do crédito rural (PRONAF), segundo Canziani (2000). 
Os impostos e as taxas considerados sobre a receita total foram: INSS na alíquota de $2,3 \%$ das receitas obtidas com venda de animais e de carne, e 1\% para taxas diversas como encargos para associações, contribuições sindicais, entre outras (Canziani, 2005). Calculou-se ICMS na alíquota de $7 \%$ sobre a receita obtida com a venda de carne (PARANÁ, 2007). O Imposto Territorial Rural (ITR) não foi considerado porque a propriedade possui área menor que 30 ha, portanto, é imune à cobrança (BRASIL, 1997).

As despesas gerais corresponderam a $1 \%$ do custo variável, exceto assistência técnica, transporte dos animais, impostos e taxas (Sistema FAEP, 2005).

A mão-de-obra considerada nos quatro sistemas de produção foi a de um funcionário com um salário mínimo regional, com custo anual compreendido por 12 salários mais encargos trabalhistas de $40 \%$ sobre o total anual (Sistema FAEP, 2005). Considerou-se contratação de mãode-obra temporária nos períodos de maior demanda de trabalho, num total de 48; 48; 60; 72 diárias nos sistemas de terminação em pastagem com e sem desmame dos cordeiros, com creep feeding e no confinamento, respectivamente.

Para estabelecer o custo de oportunidade do capital investido, considerou-se o valor da terra, do rebanho, das benfeitorias, das máquinas e dos equipamentos. Optou-se por considerar a taxa de $3 \%$ ao ano sobre o valor médio histórico da terra e essa taxa foi definida pela diminuição da valorização da terra sobre a taxa de juros do mercado (média $6 \%$ ao ano) (Canziani, 2005). Utilizou-se o mesmo critério para o investimento em animais, ou seja, o rebanho de ovinos. Para as benfeitorias, máquinas e equipamentos, os juros por ano foram calculados para cada bem individualmente pela fórmula: valor médio de cada bem, ou seja, (valor final + valor inicial) / 2, multiplicado pela taxa de juros de $6 \%$ ao ano (Canziani, 2005).

Todos os preços utilizados nos cálculos foram os praticados no ano de 2007, obtidos por consulta à lista de preços pagos pelo produtor da SEAB-PR (2007) e quando não disponíveis na mesma, por meio de orçamentos. Os preços de venda foram estabelecidos com base naqueles praticados na região, já que não foram encontradas tabelas com preços históricos, sendo R 3,50 o quilo de cordeiro vivo terminado com $32 \mathrm{~kg}$ e $\mathrm{R} \$ 13,50$ o quilo da carne inspecionada.

Com todos os itens que compõem o custo de produção de ovinos, elaborou-se uma planilha com divisão dos custos em: variável, operacional efetivo, operacional total, fixo e total de produção. Como custo fixo considerou-se aquele que não variou conforme o nível de produção, e variável, o oposto. O custo operacional total foi o custo variável total acrescido da depreciação de benfeitorias, máquinas e equipamentos e pasto (Matsunaga et al., 1976) e, como custo operacional efetivo, aquele que representou todas as despesas explícitas atribuídas à produção (Lopes et al., 1999), que nesse caso correspondeu ao custo variável total.

As receitas da atividade foram compostas pela venda de animais para reprodução, venda de cordeiro para abate ou de carne congelada e venda de animais por descarte (ovelhas e rufiões). O cálculo dos custos e das receitas permitiu realização das análises econômicas. A margem bruta foi obtida ao subtrair da receita bruta o custo variável total; enquanto a margem líquida foi obtida ao subtrair o custo total da margem bruta (Canziani, 2005). A lucratividade foi a margem líquida dividida pela receita bruta, e rentabilidade, margem líquida divida pelo investimento total (Lopes \& Magalhães, 2005). O ponto de equilíbrio foi calculado pela divisão do custo variável total pela receita bruta multiplicado por 100, e definiu o percentual da receita bruta a partir do qual começa o lucro. Calculou-se o custo de produção de carcaça por kg pela divisão do custo total de produção pela quantidade de carcaça produzida. A margem por kg de cordeiro para abate ou de carcaça foi obtida ao subtrair do valor de receita total o custo total por kg de cordeiro para abate ou carcaça e esse valor foi dividido pela quantidade produzida.

O fluxo de caixa foi realizado deduzindo-se da receita a despesa (custo variável e mão-de-obra) e resultou no saldo nominal, que foi corrigido ano a ano por meio da taxa de juros de 6\% ao ano para gerar o saldo real (Noronha, 1987). No ano 1 , somou-se o valor total do investimento à despesa; e no ano 10, esse valor corrigido entrou no cálculo como receita. A correção para benfeitorias, máquinas e equipamentos foi obtida pelo cálculo: valor inicial - (10 anos $\times$ depreciação anual), que representa o valor dos bens decorridos dez anos. Para a terra considerou-se como valor final o valor inicial (Canziani, 2005). Considerou-se esse fluxo de caixa do período de dez anos para cálculo do valor presente líquido (VPL), da taxa interna de retorno (TIR) e relação benefício/custo (B/C), em cada sistema de terminação por meio de planilhas no Excel (Microsoft Corporation, 2003) conforme Guimarães \& Canziani (2004).

Os resultados obtidos no experimento (etapa 1 ) foram analisados por meio do programa computacional Statistical Analysis System (SAS, 2001). A análise de variância foi feita utilizando-se o modelo linear geral (GLM) e as médias foram comparadas pelo teste Tukey a 5\% de significância. Os resultados econômicos (etapa 2) foram obtidos em cálculos em planilhas elaboradas no Excel (Microsoft Corporation, 2003), comparados por meio de análises descritivas. 


\section{Resultados e Discussão}

Constataram-se diferenças $(\mathrm{P}<0,05)$ no ganho médio diário e no rendimento de carcaça entre os sistemas, que foram maiores nos cordeiros confinados. A idade de abate foi inferior $(\mathrm{P}<0,05)$ para os cordeiros confinados, com o maior valor para cordeiro terminado após desmame em pasto. No entanto, em todos os sistemas os cordeiros foram abatidos com idade inferior a 132 dias (Tabela 1). A mortalidade dos cordeiros foi maior nos sistemas com desmame e, nos sistemas em pasto, a principal causa foi verminose. A diferença de manejo ocorreu somente na terminação.
A suplementação alimentar nos sistemas com cordeiros desmamados terminados em pasto e naqueles sem creep feeding refere-se à silagem pré-secada necessária no mês de maio para as ovelhas, no qual havia baixa disponibilidade de pasto. No creep feeding, o aumento nesse custo deve-se ao fornecimento de concentrado (20\% PB) aos cordeiros, que representou gasto de $\mathrm{R} \$ 568,22$, o que significou $\mathrm{R} \$ 5,57$ por cordeiro terminado ou $\mathrm{R} \$ 0,13 /$ cordeiro/dia. No confinamento, o valor gasto com alimento volumoso foi $\mathrm{R} \$ 42,98$ e com concentrado foi $\mathrm{R} \$ 20,54$, o que totalizou $\mathrm{R} \$ 63,52$ por cordeiro terminado (R\$ 1,86/cordeiro/dia) e representou 18,8\% do custo-caixa (custo variável + mão-deobra permanente) para produção nesse sistema (Tabela 2).

Tabela 1 - Resultados produtivos obtidos nos sistemas de terminação

\begin{tabular}{|c|c|c|c|c|}
\hline \multirow{2}{*}{ Sistema de terminação/Resultado } & \multicolumn{2}{|c|}{ Com desmame } & \multicolumn{2}{|c|}{ Sem desmame } \\
\hline & Pasto & $\overline{\text { Confinamento }}$ & Sem creep $^{1}$ & Com creep \\
\hline Ganho médio diário (g) & $107 c$ & $437 \mathrm{~b}$ & $281 b$ & $282 \mathrm{a}$ \\
\hline Mortalidade dos cordeiros (\%) & 10 & 8 & 3 & 3 \\
\hline Tempo de terminação (dias) ${ }^{2}$ & $71 \mathrm{a}$ & $34 c$ & $41 b$ & $45 b$ \\
\hline Idade de abate dos cordeiros (dias) & 131c & $94 \mathrm{a}$ & 101b & $105 b$ \\
\hline Rendimento de carcaça (\%) & $40,20 c$ & $48,22 \mathrm{a}$ & $45,40 b$ & $46,70 b$ \\
\hline Peso médio da carcaça resfriada $(\mathrm{kg})$ & $12,86 \mathrm{c}$ & $15,43 a$ & $14,53 b$ & $14,94 b$ \\
\hline
\end{tabular}

Médias na mesma linha seguidas de letras iguais não diferem pelo teste de Tukey $(P>0,05)$.

${ }^{1}$ Período de 60 dias de idade dos cordeiros até abate com $32 \mathrm{~kg}$.

${ }^{2}$ Creep = suplementação em creep feeding ( $1 \%$ peso do cordeiro).

Tabela 2 - Custo anual (R\$/ano) da produção de ovinos com sistemas de terminação para venda de carne

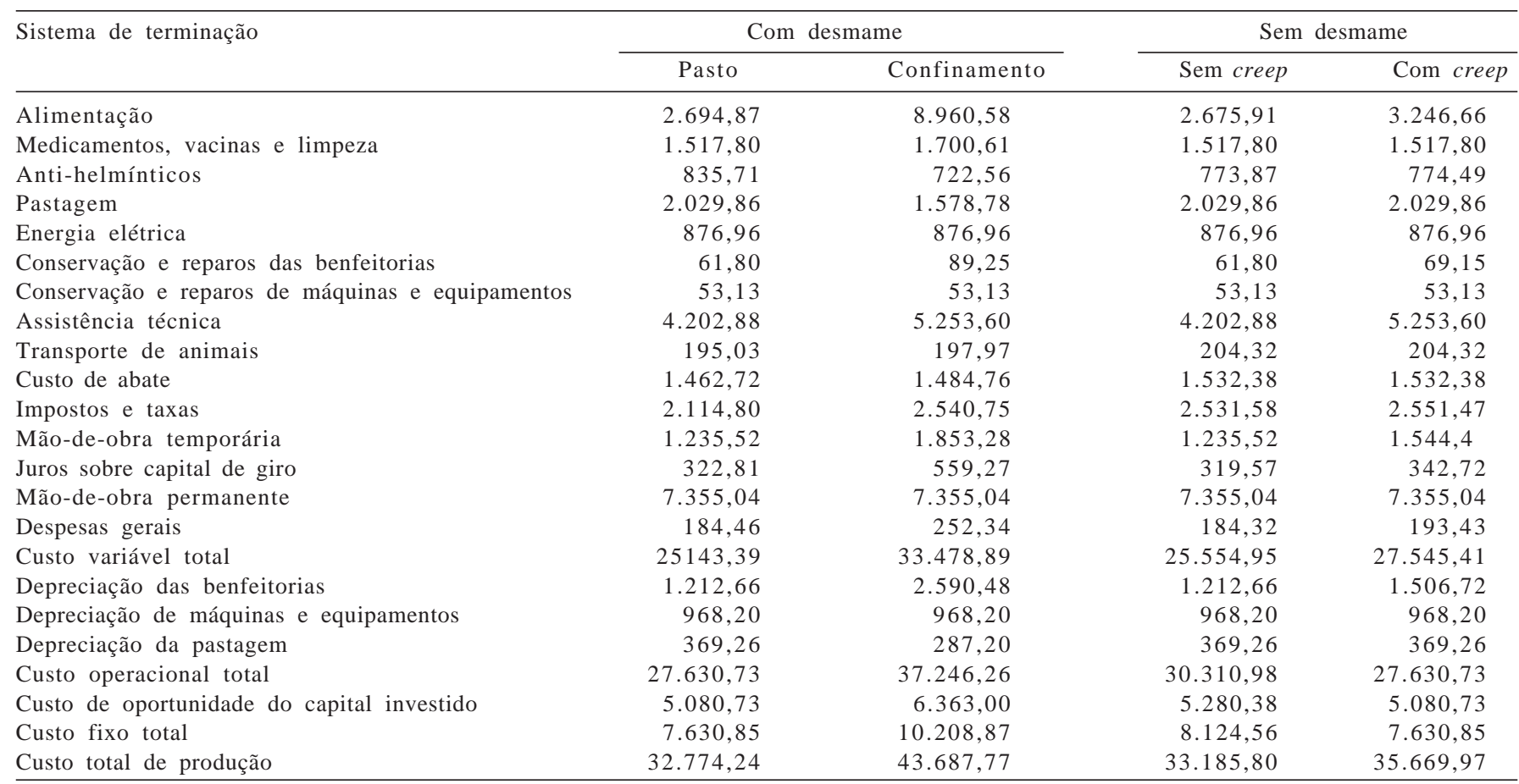

Nota: O custo com pastagem inclui semente de azevém para o inverno, adubo 05-25-25, calcário e aluguel de trator.

Despesas com medicamentos não incluem anti-helmínticos.

Custo variável total: soma dos itens alimentação até despesas gerais.

Custo operacional total: soma dos itens alimentação até depreciação da pastagem.

Custo fixo total: soma dos itens depreciação de máquinas e equipamentos até custo de oportunidade do capital investido.

Custo total de produção: soma do custo variável total e custo fixo total. 
O custo com medicamentos foi mais elevado no confinamento ( $\mathrm{R} \$ 1.700,61)$ devido ao gasto maior com coccidiostáticos, pois os animais apresentaram elevada infecção por Eimeria spp. Entre os demais sistemas, o custo com medicamentos não diferiu ( $\mathrm{R} \$ 1.517,80)$. O uso de anti-helmínticos para os cordeiros desmamados terminados em pasto foi maior que nos demais sistemas, com gasto anual de $\mathrm{R} \$ \mathbf{8 3 5}, 71$, em decorrência da maior necessidade de desverminações. Cordeiros desmamados confinados necessitaram de menor gasto com antihelmíntico (R\$ 722,56) e, nos sistemas com e sem creep feeding, esse gasto foi de $\mathrm{R} \$ 774,49$ e $\mathrm{R} \$ 773,87$, respectivamente, custo esse que se relacionou ao tempo de terminação. Portanto, cordeiros desmamados terminados em pasto necessitaram de 35\% mais de anti-helmíntico em comparação aos dos sistemas sem desmame, e 63\% mais em relação aos do confinamento. O custo com anti-helmíntico foi o custo variável que diferenciou o sistema desmamado do sem desmame em pasto, e elevou também os juros sobre o capital de giro e as despesas gerais da terminação de cordeiro desmamado em pasto. Consequentemente, a diferença de custo de produção deveu-se ao gasto com anti-helmíntico.

O custo operacional efetivo representou cerca de $75 \%$ do custo total de produção de ovinos nos quatro sistemas com venda de carne (Tabela 2). O menor custo operacional efetivo foi observado no sistema sem desmame dos cordeiros e com terminação em pastagem, que foi próximo ao de cordeiros não-desmamados terminados em pastagem. $\mathrm{O}$ maior custo foi observado no confinamento e foi 31\% superior ao menor custo (Tabela 2). A mão-de-obra representou 31,1; 30,6 e 29,4\% do custo operacional total nos sistemas de cordeiros desmamados terminados em pasto; e sem desmame terminados em pasto e com creep feeding, e correspondeu ao maior percentual desse custo nos três sistemas (Figura 1). No confinamento, a mão-deobra representou o segundo maior custo operacional total $(24,8 \%)$ e foi inferior ao custo com alimentação $(28,3 \%)$.

A análise da terminação de bovinos em confinamento realizada por Lopes \& Magalhães (2005) indicou como os itens que mais influenciaram no custo operacional efetivo da atividade, em ordem decrescente: a aquisição de animais (68,4\%), a alimentação (22,3\%) e as despesas diversas representadas por depreciação; conservação, impostos, frete e energia elétrica (4,32\%); a mão-de-obra (3,9\%); e as despesas com vacinas, antiparasitários e outros medicamentos (0,93\%). Esses valores diferem do confinamento de cordeiros, que apresentou como os três principais custos operacionais: alimentação (33,4\%), mão-de-obra (23,7\%) e conservação e depreciação de benfeitorias, máquinas e equipamentos (13,9\%) (Figura 1 ).

O custo fixo não foi desembolso para o produtor. No entanto, os custos com depreciação e custo de oportunidade do capital investido somaram quantia elevada, superior a R \$ 7.100,00 em todos os sistemas (Tabela 2). Portanto, esses valores devem ser considerados nos cálculos, pois esses fatores devem ser diretamente remunerados com a atividade. No caso da depreciação, esse valor deveria ser reserva contábil destinada a gerar fundos para substituição dos bens produtivos; dessa forma, o produtor recuperaria o bem o repondo quando esse se tornar obsoleto e com problemas para sua utilização (Canziani, 2005). O mesmo autor considera que o custo de oportunidade do capital investido representa o valor que o produtor teria como remuneração caso aplicasse o dinheiro em investimento alternativo, e, nesse caso, a comparação mais indicada seria com a caderneta de poupança (6\% ao ano), devendo-se considerar a valorização da terra, utilizado de $3 \%$ a $5 \%$ ao ano.

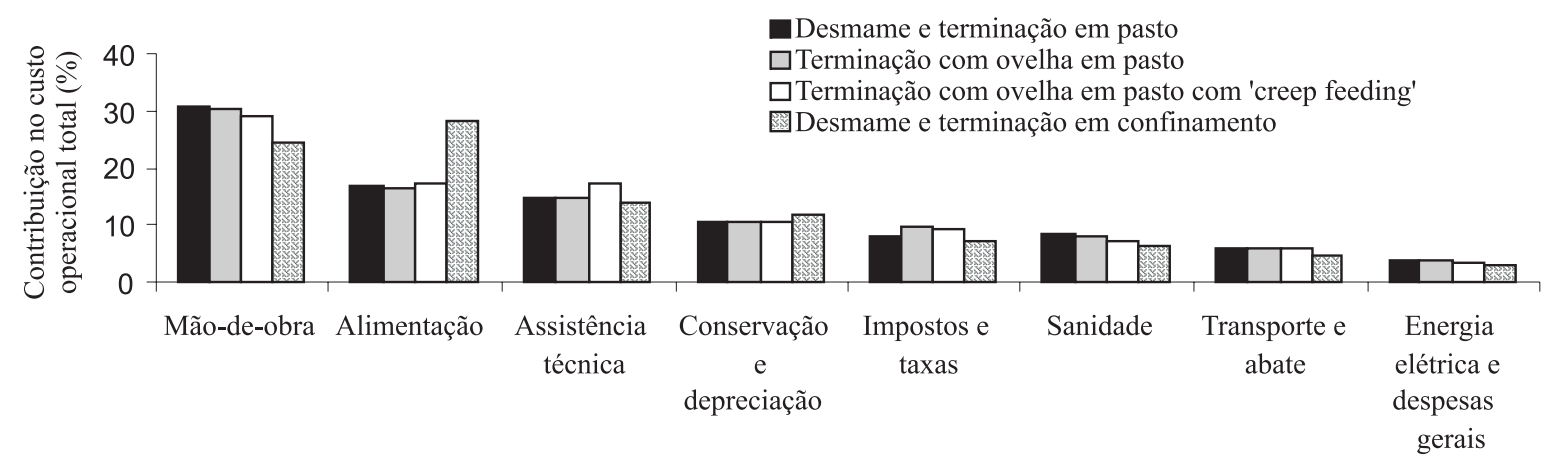

Figura 1 - Percentual de contribuição dos itens componentes do custo operacional total para venda de carne. 
Se o produtor optar pela venda de cordeiros terminados vivos na propriedade, sem entrega dos animais, em vez da venda de carne congelada embalada, ocorrem alterações. O gasto com transporte e abate dos animais não existiria; conservação e reparos de máquinas e equipamentos ( R\$ 24,15/ano) e consumo de energia elétrica também seriam reduzidos pelo fato de não haver necessidade de freezer na propriedade para armazenar a carne. Além disso, os juros sobre capital de giro e impostos e taxas também reduziriam; os juros, por haver menos capital empatado para produzir, e os impostos, por não haver pagamento do ICMS (7\% sobre carne comercia-lizada). Em relação ao custo fixo, haveria diminuição na depreciação de máquinas e equipamentos ( $\mathrm{R} \$ 439,00$ ). Dessa forma, o custo total de produção, sem o abate dos animais, seria $\mathrm{R}$ \$28.744,20; R \$28.685,85; R \$31.161,47 e R \$ 39.224,61 nos sistemas de cordeiros desmamados terminados em pasto, sem desmame terminados em pasto, sem desmame com creep feeding e desmamados confinados, respectivamente.

A receita obtida com venda de cordeiros terminados para abate foi maior nos sistemas sem desmame, devido, exclusivamente, ao maior número de animais vendidos (102 cordeiros, que no sistema com desmame e terminação em pasto foi de 98 cordeiros e no confinamento, 99 cordeiros). Quando se considerou a venda de carcaças, o sistema sem desmame com creep feeding foi o que apresentou maior receita, apenas R \$193,08 superior à do sistema sem desmame e sem suplementação (Tabela 3). Apesar de maior mortalidade observada no confinamento, o rendimento de carcaça, $48,22 \%$ (Tabela 1 ), foi maior que a dos demais sistemas, o que gerou quantidade de carne produzida $(1.524,36 \mathrm{~kg})$ superior ao cordeiro sem desmame terminado em pasto $(1.511,95 \mathrm{~kg})$. A menor receita foi observada no sistema de cordeiro desmamado terminado em pasto, pois esse sistema, além de apresentar o menor número de animais terminados, teve baixo rendimento de carcaça, 40,20\% (Tabela 1), com produção total de 1.218,93 kg de carne. No caso de cordeiro desmamado, observou-se menor redução da receita ao comparar venda de cordeiro e de carne, que foi de 19\% (Tabela 3); nos demais sistemas, essa redução de receita foi de 29; 27 e 29\% no confinamento, sem desmame em pasto e com creep feeding, respectivamente. A venda de animais para outros produtores representou elevada quantia na receita, em média 39\% da receita total. Portanto, os produtores devem selecionar um percentual do rebanho para vender como matrizes, pois isso resulta em importante aumento de receita.

Com a venda de cordeiro vivo terminado com $32 \mathrm{~kg}$ de peso corporal, somente no caso de cordeiros terminados sem desmame em pastagem verificou-se margem bruta e líquida positivas. Entretanto, todos os sistemas apresentaram resultado econômico negativo, ou seja, prejuízo (Tabela 4) considerando o preço de venda praticado de $\mathrm{R} \$ 3,50$ o quilo de cordeiro vivo terminado e $\mathrm{R} \$ 13,50$ o quilo da carne inspecionada. Quando a propriedade apresenta margem líquida e bruta negativas, os custos não estão sendo cobertos pela receita gerada (Canziani, 2005) e se a situação for mantida assim, em médio ou longo prazo será levada à descapitalização progressiva, com inviabilidade da atividade. Assim, é muito importante a conscientização das empresas compradoras e das cooperativas de produtores quanto ao preço de venda de animais vivos e de carne no Brasil, de modo que sejam buscados preços mais condizentes com os custos da atividade.

Para venda de cordeiro vivo terminado, o sistema de cordeiro sem desmame em pasto até a terminação apresentou margem bruta e líquida superiores aos demais. Todos os sistemas apresentaram resultado econômico negativo.

Na avaliação da margem bruta (Tabela 4), somente no sistema com confinamento não houve sobra de dinheiro;

Tabela 3 - Receitas anuais nos sistemas de terminação de cordeiros obtidas em duas formas de venda da produção: animais vivos terminados e carne congelada embalada

\begin{tabular}{|c|c|c|c|c|}
\hline & \multicolumn{2}{|c|}{ Com desmame } & \multicolumn{2}{|c|}{ Sem desmame } \\
\hline & Pasto & Confinamento & Sem creep & Com creep \\
\hline \multicolumn{5}{|l|}{ Receita (R\$) } \\
\hline Venda de cordeiros terminados & $10.921,64$ & $11.086,24$ & $11.441,75$ & $11.441,75$ \\
\hline Venda de animais como matrizes & $12.723,40$ & $12.761,51$ & $13.006,79$ & $13.006,79$ \\
\hline Venda de carne congelada & $16.455,59$ & $20.578,83$ & $20.411,26$ & $20.604,34$ \\
\hline Venda de animais como matrizes & $12.723,40$ & $12.761,51$ & $13.006,79$ & $13.006,79$ \\
\hline Receita total & $29.178,99$ & $33.340,35$ & $33.418,05$ & $33.611,13$ \\
\hline
\end{tabular}


os valores positivos nos demais sistemas podem dar a falsa impressão ao produtor de que houve lucro, mas na realidade não houve a remuneração de muitos custos, que normalmente não são considerados nas atividades agropecuárias pelos produtores. Portanto, não se deve avaliar uma atividade com base nesse valor que aparentemente está disponível como lucro. Mesmo no sistema mais rentável, cordeiro sem desmame em pasto, somente após venda de percentual superior a 64,13\% da produção, houve lucro ao considerar o custo total de produção (Tabela 4).

Para remunerar todos os fatores de produção, o preço mínimo de venda do quilo de cordeiro vivo deveria ser em torno de R \$ 8,35 no confinamento e superior a $\mathrm{R} \$ 4,80$ nos demais sistemas, valor distante dos $\mathrm{R} \$ 3,50$ praticados na região (Tabela 4). O valor de venda praticado foi próximo ao preço de nivelamento calculado para o custo variável em três sistemas, com exceção do confinamento (Tabela 4). A lucratividade, que, segundo Lopes \& Magalhães (2005) deve ser usada para comparar sistemas de produção, foi positiva somente no sistema de terminação de cordeiros sem desmame em pasto, enquanto os outros dois foram inviáveis nas condições apresentadas.

Na análise da realização de abate dos cordeiros para venda de carne, somente o sistema com desmame e confina- mento apresentou margem líquida negativa (Tabela 4). O sistema de terminação sem desmame em pasto apresentou a maior margem líquida, que foi $\mathrm{R} \$ 4.730,39$ superior à obtida com a venda de cordeiro terminado sem abate. No sistema em pasto com uso de creep feeding, o aumento do custo em relação ao sistema sem desmame em pasto foi de $\mathrm{R} \$ 2.484,17$ por ano e o aumento da receita, de $\mathrm{R} \$ 193,08$, portanto o aumento de receita não atingiu o aumento de custo. Com abate, o preço de nivelamento para cobrir o custo total de produção seria em torno de $\mathrm{R} \$ 15,00$ o quilo da carne nos sistemas sem desmame, $\mathrm{R} \$ 16,50$ com desmame e terminação em pasto e R $\$ 20,30$ com confinamento. O preço praticado de $\mathrm{R} \$ 13,50$ torna a atividade viável, mesmo sendo abaixo do preço de nivelamento em relação ao custo total devido ao acréscimo de aproximada-mente 37\% na receita pela venda de animais como matrizes. Ressalta-se que não é comum nas propriedades de ovinos a venda de carne devidamente inspecionada, o que dificultou estimativa de preço real de venda do produto; no entanto, esse tipo de carne poderia ser vendido por preço mais elevado, ao se considerar a qualidade da carne ao consumidor, que resultaria em maior lucratividade. A ideia de venda de carne, ora proposta, sugere a aquisição e organização de abatedouros pelos produtores ou por grupos organizados e não objetiva

Tabela 4 - Resultados anuais de cordeiros nos diferentes sistemas de terminação

\begin{tabular}{|c|c|c|c|c|}
\hline & \multicolumn{2}{|c|}{ Com desmame } & \multicolumn{2}{|c|}{ Sem desmame } \\
\hline & Pastagem & Confinamento & Sem creep & Com creep \\
\hline \multicolumn{5}{|l|}{ Resultado anual } \\
\hline Margem bruta = RT-COEf $(\mathrm{R} \$)$ & $1.741,66$ & $-5.946,66$ & $2.603,52$ & 632,94 \\
\hline Margem líquida = RT-COT (R\$) & $-279,25$ & $-9.263,33$ & 582,60 & $-1.682,03$ \\
\hline Ponto de equilíbrio (\%) & 67,76 & 110,97 & 64,13 & 74,26 \\
\hline Preço de nivelamento (R\$) & 5,13 & 8,35 & 4,80 & 5,55 \\
\hline Lucratividade (\%) & $-1,18$ & $-38,84$ & 2,38 & $-6,88$ \\
\hline Rentabilidade (\%) & $-0,26$ & $-6,61$ & 0,55 & $-1,49$ \\
\hline Margem líquida/kg de cordeiro (R\$) & $-0,09$ & 0,18 & 0,18 & $-0,51$ \\
\hline Investimento total $(\mathrm{R} \$)$ & $106.636,95$ & $140.218,24$ & $106.636,95$ & $112.679,16$ \\
\hline Produtividade (R\$/ovelha) & 179,87 & 221,60 & 224,05 & 211,18 \\
\hline Ponto de equilíbrio (\%) & 68,72 & 92,76 & 60,38 & 67,43 \\
\hline Preço de nivelamento (R\$) & 16,45 & 20,29 & 13,35 & 14,85 \\
\hline Lucratividade (\%) & 5,09 & $-11,95$ & 15,90 & 9,58 \\
\hline Rentabilidade (\%) & 0,92 & $-2,04$ & 3,28 & 1,92 \\
\hline Margem líquida/kg de cordeiro (R\$) & 1,22 & $-2,61$ & 3,51 & 2,11 \\
\hline Investimento total (R\$) & $161.774,95$ & $195.356,24$ & $161.774,95$ & $167.817,16$ \\
\hline
\end{tabular}

Nota: $\mathrm{RT}$ = receita total; $\mathrm{CV}$ = custo variável; COT = custo operacional total; COEf = custo operacional efetivo; CT = custo total de produção.

A produtividade se refere ao valor em reais gerado por cada ovelha do rebanho.

$\mathrm{O}$ ponto de equilíbrio referiu-se ao percentual da receita total necessário para cobrir o custo total de produção quando se realiza também a venda de animais descarte e matrizes.

O preço de nivelamento referiu-se ao preço mínimo de venda para cobrir o custo total de produção quando se realiza também a venda de animais descarte e matrizes. 
fomentar o abate clandestino, que já ocorre no país de forma intensa. No estado do Paraná, há alguns produtores organizados em Cooperativas que realizam o abate dos animais com a devida inspeção e têm consumidores garantidos para seus produtos, como açougues e restaurantes, para os quais entregam a carne. Dessa forma, deve-se pensar muito seriamente também na logística de distribuição do produto ao consumidor.

Para a venda de animais sem abate, o valor presente líquido de todos os sistemas foi negativo, o que significou que, à taxa de desconto de $6 \%$ ao ano, a soma das receitas do período de dez anos foi menor que o investimento na atividade.

A taxa interna de retorno deve ser igual ou superior à taxa de juros de mercado (a caderneta de poupança e a referência de comparação) e essa taxa positiva indica que o capital investido na atividade é recuperado e o saldo disponível a cada ano rende juros iguais à taxa interna de retorno (Guimarães \& Canziani, 2004). O maior valor da taxa interna de retorno foi observado no sistema sem desmame em pasto quando se fez venda de carne (Tabela 5). A taxa interna de retorno indica a taxa de retorno sobre o capital empatado no projeto, ou seja, o conjunto do fluxo de entradas e saídas do projeto apresenta o rendimento obtido no cálculo da taxa interna de retorno. Portanto, os sistemas que apresentam taxa interna de retorno superior à $6 \%$ ao ano seriam: com e sem desmame e terminação em pasto com venda de cordeiro terminado, e para venda de carne, os três sistemas, com exceção do confinamento (Tabela 5).

O benefício/custo foi maior no sistema sem desmame com terminação em pasto. Por essa relação, também confirmou-se que foi mais vantajoso para o produtor vender carne em vez de cordeiro vivo terminado.

Com a venda de cordeiro terminado, os indicadores econômicos para cordeiros desmamados terminados em pastagem foram superiores ao sistema com creep feeding (Tabela 5). Isso ocorreu porque o saldo nominal anual do fluxo de caixa foi maior no primeiro $(\mathrm{R} \$ 1.741,66)$ que no creep feeding (R\$ 632,94). No creep houve maior custo com alimentação dos cordeiros (concentrado) e maior investimento em benfeitorias que geraram conservação e depreciação; além disso, com a venda de cordeiro, não houve aumento de receita devido ao maior rendimento de carcaça desse sistema (Tabela 1).

Tabela 5 - Resultados anuais da produção de cordeiros nos diferentes sistemas de produção

\begin{tabular}{|c|c|c|c|c|}
\hline & \multicolumn{2}{|c|}{ Com desmame } & \multicolumn{2}{|c|}{ Sem desmame } \\
\hline & Pasto & Confinamento & Sem сreep & Com creep \\
\hline \multicolumn{5}{|l|}{ Resultado anual } \\
\hline VPL (R\$) & $-58.969,31$ & $-134.864,43$ & $-52.245,40$ & $-72.458,50$ \\
\hline TIR (\% a.a.) & 0,07 & $-5,39$ & 0,73 & $-1,01$ \\
\hline Benefício:custo & 0,09 & $-0,25$ & 0,13 & 0,03 \\
\hline VPL (R\$) & $-47.444,52$ & $-101.731,27$ & $-17.583,55$ & $-41.878,24$ \\
\hline TIR (\% а.а.) & 1,37 & $-2,29$ & 4,26 & 2,11 \\
\hline Benefício:custo & 0,27 & 0,08 & 0,48 & 0,38 \\
\hline
\end{tabular}

\section{Conclusões}

Os componentes do custo operacional total que mais influenciam o custo de produção na terminação de cordeiros com e sem desmame terminados em pasto, em ordem decrescente, são mão-de-obra e alimentação dos animais. No confinamento, esses componentes, na mesma ordem, são alimentação e mão-de-obra. Da forma como foram realizados os sistemas, para o abate dos cordeiros, aumentaram os custos de depreciação, conservação e reparos, com transporte e abate dos animais e do ICMS (imposto sobre circulação de mercadorias e prestação de serviços). Entretanto, o aumento de receita supera o dos custos, o que resulta em maior lucratividade e rentabilidade da venda de carne em relação à venda de cordeiro vivo terminado. Dos sistemas estudados, aquele sem desmame dos cordeiros terminados em pasto com venda de carne é o único que não gera prejuízo, o que indica necessidade de elevada eficiência no uso dos recursos na criação de ovinos. O sistema de confinamento realizado nas condições apresentadas para terminação dos cordeiros com dieta à base de feno de alfafa e concentrado (20\% PB na MS) e uso de aprisco suspenso apresenta alto custo de produção, por isso, é economicamente inviável. Os sistemas de produção de ovinos para carne, da forma como foram realizados, apresentam indicadores econômicos (valor presente líquido, 
taxa interna de retorno e benefício:custo) com valores abaixo daqueles desejados; os melhores resultados são observados no sistema de cordeiros terminados com as mães em pastagem.

\section{Agradecimentos}

Ao CNPq, pela concessão da bolsa e pelo auxílio financeiro para o projeto, à UFPR e a todos os professores e estagiários que colaboraram para execução deste trabalho.

\section{Literatura Citada}

BRASIL. Instrução Normativa SRF n ${ }^{\text {43, de }} 7$ de maio de 1997. Dispõe sobre a apuração do imposto sobre a propriedade territorial rural e dá outras providências. Diário Oficial [da] República Federativa do Brasil. Brasília, DF, 7 mai. 1997. Disponível em: <http://www.receita.fazenda.gov.br/Legislacao/ ins/Ant2001/1997/insrf04397.htm>. Acesso em: 2/2/2007.

BROWN, T.H. The early weaning of lambs. Journal of Agricultural Science, v.23, p.191-204, 1994.

CAÑEQUE, V.; HUIDOBRO, F.R.; DOLZ, J.F. La canal de cordero. In: PRODUCCIÓN DE CARNE DE CORDERO, 1992, México. Anais... México: Ministério de Agricultura, Pesca y Alimentación, 1992. p.367-436.

CANZIANI, J.R.F.; DOSSA, D. In: SERVIÇO NACIONAL DE APREndizAgem RURAL: Administração Regional do Paraná. Avaliação Técnica e Econômica da Bovinocultura de Corte - ATEPEC. Curitiba: SENAR-PR, 2000. 42p.

CANZIANI, J.R.F. O cálculo e a análise do custo de produção para fins de gerenciamento e tomada de decisão nas propriedades rurais. Curitiba: DERE/SCA/UFPR, 2005. 19p. (Material Didático).

COMPANHIA PARANAENSE DE ENERGIA - COPEL. Mercado de energia elétrica da COPEL. Disponível em: <http:// www.copel.com/pagcopel.nsf/arquivos/bri04_07port/\$FILE/ bri04_07port.pdf.>. Acesso em 10/5/2007.

FRESCURA, R.B.M.; PIRES, C.C.; ROCHA, M.G. et al. Sistemas de alimentação na produção de cordeiros para abate aos 28 kg. Revista Brasileira de Zootecnia, v.34, n.4, p.1267-1277, 2005.

GORDON, H.M.; WHITLOCK, H.N. A new technique for counting nematode egg in sheep faeces. Journal of the Council of Science Industry and Research, v.12, n.1, p.50-52, 1939.

GUimARÃES, V. Di. A.; CANZIANI, J.R. Análise econômica, financeira e de decisão. Curitiba: DERE/SCA/UFPR, 2004. 34p. (Material Didático).
HOFFMANN, R.; ENGLER, J.J.C.; SERRANO, O. Administração da empresa agrícola. 3.ed. São Paulo: Pioneira, 1981. 325p.

LOPES, M.A.; MAGALHÃES, G.P. Análise da rentabilidade da terminação de bovinos de corte em condições de confinamento: um estudo de caso. Arquivo Brasileiro Medicina Veterinária Zootecnia, v.57, n.3, p.374-379, 2005.

LOPES, M.A.; JUNQUEIRA, L.V.; ZAMBALDE, A.L. Desenvolvimento de um sistema computacional para determinação do custo de produção do gado de corte. Revista Brasileira de Agroinformática, v.2, n.2, p.105-116, 1999.

MATARAZZO, D.C. Análise financeira de balanços. 4.ed. São Paulo: Atlas, 1997. 463p.

MATSUNAGA, M.; BEMELMANS, P.F.; TOLEDO, P.E.N. Metodologia de custo de produção utilizado pelo IEA. Agricultura em São Paulo, v.23, n.1, p.123-139, 1976.

MICROSOFT CORPORATION. Microsoft office Excel 2003. [Programa de computador]. Washington, 2003.

NERES, M.A.; GARCIA, C.A.; MONTEIRO, A.L.G. et al. Níveis de feno de alfafa e forma física da ração no desempenho de cordeiros em creep feeding. Revista Brasileira de Zootecnia, v.30, n.3, p.941-947, 2001 (supl. 1).

NORONHA, J.F. Projetos agropecuários: administração financeira, orçamentos e viabilidade econômica. 2.ed. São Paulo: Atlas, 1987. v.1. 269p.

NATIONAL RESEARCH COUNCIL - NRC. Nutrient requirements of sheep. Washington, D.C.: National Academy Press, 1985. 99p.

PARANÁ. Decreto $\mathrm{n}^{\circ}$ 882, de 29 de maio de 2007. Dispõe sobre o crédito presumido de ICMS para as operações com carnes e produtos resultantes do abate em frigoríficos e dá outras providências. Diário Oficial N $\mathbf{N}^{\mathbf{7}}$ 7481, Curitiba, PR, 29 maio 2007. Disponível em: <http://www.sefanet.pr.gov.br/SEFADocumento/ Arquivos/2200700882.pdf $>$. Acesso em: 28/10/2007.

POLI, C.H.E.C.; CARVALHO, P.C.F. Planejamento alimentar de animais: proposta de gerenciamento para o sistema de produção à base de pasto. Pesquisa Agropecuária Gaúcha, v.7, n.1, p.145-156, 2001.

REIS, D.L. Estudo técnico e econômico da propriedade rural. Belo Horizonte: Informe Agropecuário, v.12, n.143, p.23-38, 1986.

RIBEIRO, T.M.D.; MONTEIRO, A.L.G.; PRADO, O.R.P. et al. Desempenho animal e características das carcaças de cordeiros em quatro sistemas de produção. Revista Brasileira de Saúde e Produção Animal, v.10, p.366-378, 2009.

SECRETARIA DA AGRICULTURA E DO ABASTECIMENTO DO PARANÁ - SEAB-PR. Preços pagos pelo produtor, trimestre: fevereiro-2007. Disponível em: <http://www.pr.gov.br/seab/>. Acesso em: 20/4/2007.

SISTEMA FAEP. Federação da Agricultura do Estado do Paraná. Sistema de acompanhamento do custo de produção do leite no Paraná. 1.ed. Curitiba: FAEP, 2005. 125p.

STATISTICAL ANALYSIS SYSTEM - SAS. Versão 8.2. [Programa de computador]. Cary: SAS Institute, 2001. (8 CD-ROM). 